\title{
A modernização ecológica pode ser adaptada ao brasil?
}

\author{
Ecological modernization can be adapted to brazil?
}

\author{
Gilivã Antonio Fridrich', Nelma Baldin², Amanda Carolina de Mello3, Vanilda Galli \\ 'Mestrando em Saúde e Meio Ambiente - Universidade da Região de Joinville - (Univille) Joinville - SC \\ ${ }^{2}$ Doutora - Universidade da Região de Joinville - (Univille) Joinville - SC \\ ${ }^{3}$ Graduanda em Engenharia Ambiental e Sanitária.- Universidade da Região de Joinville - (Univille) Joinville - SC \\ ${ }^{4}$ Mestranda em Saúde e Meio Ambiente- Universidade da Região de Joinville - (Univille) Joinville - SC
}

\begin{abstract}
Resumo
Devido a constante poluição e degradação ambiental cada vez mais agressiva, no século XX começou-se a perceber que os recursos do planeta não eram infinitos e desde então várias propostas foram sendo criadas com o intuito de minimizar a degradação, dentre elas a Modernização Ecológica (ME). O objetivo do presente estudo foi discutir as limitações do Brasil, quais elementos da ME seriam passíveis de implementação considerando a realidade socioambiental brasileira e quais seus consequentes benefícios ao país. Metodologicamente, fez-se um estudo teórico após a leitura prévia e a análise crítica do artigo "Modernização ecológica no Brasil: limites e perspectivas" de autoria de Bruno Milanez (2009), de maneira a discutir as principais limitações da ME e os benefícios da implementação desses elementos. Após a revisão da literatura constatou-se que a ME, apesar de trazer aspectos positivos, não irá resolver os problemas da sociedade brasileira. Existe, assim, a necessidade de se pensar numa nova política ambiental e aliada à questão governamental a participação de uma população ambientalmente conscientizada, em todas as esferas, de forma maciça. Somente assim poderemos cogitar a possibilidade de alcançar ações concretas, dentre essas, a efetivação da ME no Brasil e em diferentes cenários que venham beneficiar o meio ambiente.
\end{abstract}

Palavras-chaves: Modernização ecológica; problemas ambientais; tecnologia limpa; conscientização; política ambiental.

\begin{abstract}
Due to constant pollution and increasingly aggressive environmental degradation in the twentieth century people began to realize that the planet's resources were not infinite and since then several proposals were created in order to minimize degradation, among them the Ecological Modernization ( ME ). The aim of this study was to discuss the limitations of Brazil, which elements of the ME would be capable of implementation on the Brazilian environmental reality and what their consequent benefits to the country. The methodology used we carried out a theoretical study prior reading and critical analysis of the article "Ecological Modernization in Brazil: limits and perspectives " written by Bruno Milanez 2009, in order to discuss the main limitations of the ME and the benefits of implementing these elements . After reviewing the literature it was found that the $\mathrm{ME}$, despite bringing positive aspects, will not solve the problems of Brazilian society . There is therefore the need to think of a new environmental policy and allied to the government concerned to participate in an environmentally smartening population, in all spheres, in a massive way and only way we can entertain the possibility of achieving concrete actions, among these, the effectiveness of ME in Brazil and different scenarios that may benefit the environment .
\end{abstract}

Keywords: Ecological modernization; environmental problems; clean technology; awareness; environmental policy. 


\section{INTRODUÇÃO}

As primeiras intervenções realizadas sobre os recursos naturais e provocadas pelo homem aconteceram no momento em que os humanos passaram de nômades, caçadores ou coletores para agricultores sedentários (com residência fixa). Iniciaram-se, ali, as interferências ambientais de maneira mais agressiva e assim, consequentemente, no correr dos Séculos.

No século XX começaram a surgir as primeiras ideias de "sustentabilidade" e preservação ambiental, de modo que o homem começou a perceber que os recursos do planeta não eram infinitos e que de alguma maneira eles precisariam ser poupados. Neste sentido, tiveram inicio reuniões e encontros para tratar sobre a problemática dos recursos naturais disponíveis no planeta. Um desses encontros foi realizado no ano de 1968, em Roma, com a reunião com cientistas de países industrializados que visaram discutir o consumo e as reservas de recursos naturais não-renováveis e o crescimento da população mundial previsto para o século XXI. Outro marco histórico do Século foi no ano de 1972, em Estocolmo, onde aconteceu uma das primeiras iniciativas mundiais para organizar as relações entre o homem e a natureza. Como prosseguimento histórico, no ano de 1987, caracterizou-se, via relatórios, a iniciativa das praticas do Desenvolvimento Sustentável visando as explorações dos recursos naturais no ambiente. Desde então diversas reuniões têm sido realizadas e inúmeras propostas apresentadas, como: "Desenvolvimento sustentável", "Sustentabilidade", "Modernização Ecológica", "Educação Ambiental", entre outras.

Em relação à Modernização Ecológica (ME) - com vistas à resolução de questões ambientais, as principais críticas que essa corrente recebe' estão relacionadas à sua origem tecnocrática, ou seja, ao fato de que ela adequa o ambientalismo às necessidades do mercado, não concebe as relações de poder e o papel dos agentes, nem dá a devida atenção aos contextos sociais e às preocupações éticas (BRULLE, 2010).

É importante observar que o sucesso da ME para a tratativa de problemas ambientais depende de alguns fatores, dentre eles, a realidade socioambiental do local onde será implementada, deve-se considerar que a especificidade de cada local pode determinar a eficiência na utilização de alguns elementos da ME. Considerando o exposto, é importante analisar, de forma holística, quais as limitações na implementação da ME no Brasil, discutir o que é realmente possível e quais os consequentes benefícios socioambientais ao país, mensurando sua contribuição quando em um contexto amplo de possíveis ações para redução e/ou prevenção do dano ambiental.

O objetivo deste artigo foi discutir as limitações do Brasil e quais elementos da ME seriam passíveis de implementação, considerando a realidade socioambiental brasileira e quais seus consequentes benefícios ao país.

Para atingir-se esse objetivo, fez-se, inicialmente, a leitura e a análise crítica do artigo "Modernização ecológica no Brasil: limites e perspectivas" de autoria de Bruno Milanez (2009). A partir da leitura desse texto, buscou-se a inspiração para abordar o tema em questão (a ME) de maneira a discutir suas principais limitações e os benefícios da implementação de elementos possíveis frente à realidade socioambiental brasileira.

Nesse sentido, a metodologia utilizada no estudo foi a qualitativa por ser, esta, uma abordagem adequada para se entender a natureza de um fenômeno social, exploratório, e por proporcionar maior familiaridade com o problema em investigação bibliográfica, segundo André (2010). Por ser o artigo de Milanez elaborado a partir de contribuições de materiais nacionais e internacionais com a devida credibilidade científica, selecionaram-se as principais ideias de artigos e livros indicados pelo autor e relacionando-as direta ou indiretamente à $\mathrm{ME}$, as quais foram extraídas e discutidas criticamente por autores que nos deram suporte teórico tais como Martins e Theóphilo (2007).

\section{DEFINIÇÃO E SURGIMENTO DA MODERNIZAÇÃO ECOLÓGICA}

Alinhada com as ideias de desenvolvimento sustentável, a ME forma um corpo teórico essencialmente otimista: onde a melhora ambiental pode caminhar junto com o desenvolvimento econômico, desde que as instituições e os mecanismos econômicos sejam reformados de acordo com critérios de racionalidade ecológica. De certa forma, a ME parte de uma crítica ao caráter fragmentário, burocrático e reativo das políticas estatais ecológicas dos anos 70. Ela procura estabelecer, então, um modelo 
de regulação estatal mais flexível e participativo na geração da política ecológica (MILANEZ, 2009).

Desde o despontar dos movimentos ambientalistas, na década de 1960, os fatores de degradação têm recebido mais atenção do que os fatores de melhora da qualidade ambiental. Empresas passaram por diferentes estágios em sua relação com a questão ambiental e nos anos 1970, tomaram basicamente uma postura reativa, criando departamentos ambientais para fugir dos perigos associados com a regulação estatal.

No âmbito brasileiro, no inicio dos anos 1970 foi criada a Secretaria Especial do Meio Ambiental (SEMA) subordinada ao Ministério dos Transportes, tratando de assuntos ligados a Educação Ambiental e desenvolvimento sustentável (REIGOTA, 2012).

Nos anos 1980, muitas empresas começaram a desenvolver respostas mais substanciais com o intuito de diminuir os impactos ambientais. Essa, uma maneira de "manter suas reputações como bons cidadãos e cidadãs" (MOL e SPARGAAREN, 2000, p. 24).

Essa iniciativa levou a uma nova postura na década de 1990, quando surgiram programas para a redução de resíduos e de processos de reciclagem. Todavia, apenas no final do século XX começou-se a buscar, em certos setores empresariais, a integração completa dos objetivos econômicos e ecológicos no planejamento e na produção dos produtos.

Hajer e Versteeg (2005) esclarecem que nos ditos países desenvolvidos - e pioneiramente na Alemanha e no Japão - a ME se tornou o discurso dominante na arena ambiental desde o final dos anos de 1980. Seu nascimento deve ser entendido como reação aos discursos de desindustrialização que marcaram os debates ambientais na década de 1970.

No ano de 1982 a Secretaria do Meio Ambiente de Porto Alegre realizou o I Encontro de Educação Ambiental (EA) que se tem notícia no Brasil, repetindo o mesmo evento em 1983. Em Sorocaba, em 1984, ocorreu o Primeiro Encontro Paulista de Educação Ambiental. Embora de caráter regional, esse encontro reuniu os poucos praticantes e pesquisadores de EA, onde trataram do desenvolvimento sustentável de certo modo relacionado a ME (REIGOTA, 2012). Assim, a ME emergiu nos países industrializados como um novo discurso da política ambiental e das ciências sociais, especificamente da sociologia e da ciência política. A partir desse posicionamento, passou a servir como meio de avaliar países, regiões e setores produtivos (LENZI, 2006).

Neste setor, a Teoria da ME toma a frente e estabelece-se como um corpo de conhecimento que engloba o desenvolvimento sustentável. A ME, conclui Buttel (2000), é um novo e aprimorado sinônimo para o desenvolvimento sustentável.

Assume-se, então, que o desenvolvimento sustentável é um conceito antecessor da Teoria da $\mathrm{ME}$, audacioso e abrangente, uma vez que engloba questões sociais, econômicas e ambientais em suas proposições. Todavia, é um conceito truncado por não apresentar métodos que viabilizem soluções para os problemas ambientais, o que nos permite discordar sobre a suposta superioridade da teoria da modernização ecológica nessa perspectiva.

De acordo com Mol (1995), podemos encontrar três usos diferentes do conceito: Primeiro: a ME pode ser vista como um novo conceito que traz contribuições teóricas para um novo ramo da sociologia (Sociologia Ambiental); Uma segunda vertente, vê a ME como um conjunto de estudos da ciência social em geral que procura analisar as diferentes linhas de políticas ambientais que são vistas como propiciando um padrão mais ecológico de produção. Nesse caso, a ME coloca-se como um novo discurso ecológico que levaria a um novo "paradigma da política ambiental"; Uma terceira corrente, veria a modernização ecológica como um programa concreto de política ambiental radical colocado em andamento por partidos políticos.

Nesse sentido, como manifesta Mol (1995), em sua dimensão sociológica a teoria da ME fornece uma série de conceitos que buscam fornecer o entendimento do surgimento da degradação ambiental moderna avaliando de que forma tais sociedades reagem a esses problemas.

$\mathrm{Na}$ verdade o surgimento da $\mathrm{ME}$ está associado à tendência dos ambientalistas de se tornar em "menos radicais, mais práticos e mais orientados para a política" (HAJER, 1995, p. 47). E Mol (1995) enfatiza essa tendência ao esclarecer que a ME é uma transformação ecológica do processo de industrialização numa direção na qual a base de sustentação pode ser garantida. A ME "indica a possibilidade de superar a crise ambiental enquanto fazemos uso das instituições da modernidade, sem abandonar o padrão de modernização" (MOL, 1995, p. 58).

A importância da ME para a Sociologia Ambiental parece residir tanto na importância que 
ela confere na possibilidade de integração entre economia e ecologia como também na importância que ela confere ao Estado como um "condutor" dessa mudança. A ME admite uma valorização do padrão econômico capitalista, reconhece a importância da atuação regulamentadora do estado em questões ambientais e conhece a necessidade de movimentos ambientais para fiscalizarem de órgãos públicos (MUNCK; SOUZA, 2010)

\section{REQUISITOS QUE CONFRONTAM COM A NOSSA REALIDADE}

A ME tem sido associada principalmente aos países mais ricos, pelo fato de sua implementação exigir os seguintes requisitos:

- um sistema político aberto e democrático;

- um Estado intervencionista e legítimo com uma infraestrutura diferenciada e avançada;

- consciência ambiental social ampla e organizações ambientais bem organizadas (ONGs), que tenham recursos para impelir a uma mudança ecológica radical;

- organizações de negócios capazes de representar produtores em negociações numa base regional e setorial;

- experiência e tradição com sistemas de tornada de decisão negociada;

- um sistema detalhado de monitoração ambiental que gera dados ambientais públicos, confiáveis e satisfatórios;

- uma economia de mercado regulada pelo Estado, que controla o processo de produção e consumo;

- desenvolvimento tecnológico avançado (FRIJNS, PHUONG; MOL, 2000).

\section{DISCUTINDO AS DIFICULDADES DE IMPLEMENTAR A MODERNIZAÇÃO ECOLÓ- GICA E SEUS CONSEQUENTES BENEFÍCIOS}

A compatibilização entre crescimento econômico e proteção ambiental torna necessário que o sistema produtivo incorpore as chamadas tecnologias ambientais, que, segundo Gouldson e Murphy (1998) são quaisquer tipos de "tecnologia que reduzem o impacto absoluto ou relativo de um processo ou produto sobre o meio ambiente".

Tecnologias limpas ou preventivas não buscam tratar a poluição após sua emissão, mas sim evitar ou reduzir tais emissões antecipadamente. Seu foco são as causas da degradação ambiental e não os efeitos que são produzidos por ela. As Tecnologias limpas são fundadas no princípio de prevenção, enquanto as tecnologias de controle pautam-se no princípio de reação.

$\mathrm{O}$ desenvolvimento tecnológico proposto pela ME considera a busca pela tecnologia limpa no aumento da eficiência produtiva e visando eliminar a emissão de poluentes. No entanto, há que considerar que a relação entre empresa e proteção ambiental é muito mais complexa e vai desde a aquisição de matérias primas até o pós-consumidor (LENZI, 2006).

O que é questionável é qual o tamanho do benefício gerado ao se manter o foco no desenvolvimento de tecnologia limpa já que este é apenas uma etapa no ciclo de vida de um produto. Dessa forma é necessário considerar que a agressão ao meio ambiente durante a produção deva ser baixo, o que reduziria grande parte da poluição gerada. Deve-se também considerar que o produto gerado seja o mínimo possível prejudicial a este meio, que as matérias-primas utilizadas sejam preferencialmente renováveis ou que ao menos a quantidade de não renováveis seja reduzida (LENZI, 2006).

A escassez pode ser a razão para a elevação de preços de determinados recursos. No entanto, isso não é garantia de que a degradação cessará. É preciso que se busquem ações atuantes em todas as etapas do ciclo de vida de um produto desde que estejam ligadas direta ou indiretamente a este. Este procedimento se faz necessário para que os benefícios gerados pela ME não sejam de certa maneira anulados pelo exacerbado impacto negativo gerado nas outras etapas.

Layargues (2002) expressa que o discurso ecológico oficial defende a existência de um consumo sustentável propiciado pela aliança da reciclagem com as tecnologias limpas e eficientes, todavia, 
vários outros autores alegam que os benefícios ao meio ambiente expostos pelo discurso ecológico alternativo que confere maior importância à redução do consumismo seriam muitos maiores que aqueles do discurso oficial. E então nos resta dúvida: qual confere maior importância à reciclagem e aos investimentos em tecnologias limpas?

Seguindo este pensamento, a ME pouco contribuiria com a redução da degradação ambiental, haja vista que não adiantaria modernizar a produção e apenas durante este processo utilizar-se de medidas mitigadoras da degradação ambiental. Dessa forma, continuariam os poluidores com as práticas agressivas, mesmo que em outras etapas do ciclo de vida do produto, inclusive com a prática da obsolescência programada, onde os bens cada vez mais saem das fábricas com uma vida útil curtíssima e já programada para se tornarem inúteis logo após sua aquisição. Ou, ainda, prevendo-se a questão da obsolescência simbólica, que orientada pela mídia e propaganda induz o descarte de produtos ainda funcionalmente operantes apenas por uma questão de "modismo".

O sistema capitalista tem como base a lei da oferta e da procura, ou seja, o consumo. Desta maneira para o sistema funcionar a população precisa estar constantemente comprando o máximo possível para manter a economia "girando". A abordagem de mercado da modernização ecológica concentra-se nas mudanças que ocorrem no âmbito das empresas e da tecnologia. Seu enfoque é econômico, empresarial e tecnológico. Pressupõe-se que empresários e empresas sejam os principais agentes da mudança e que as principais transformações a serem privilegiadas se circunscrevem no âmbito do próprio mercado. Num nível mais geral, essa abordagem incorpora os preceitos de mercado para guiar as políticas ambientais.

Seguindo o pensamento exclusivamente capitalista praticado pela grande maioria das empresas no Brasil, o ambientalmente correto está desempenhando um papel muito maior de agregação de valor ao produto do que realmente de contribuição para o meio ambiente. A modernização deve existir, entretanto, ela não deve ser praticada com finalidade exclusivamente econômica. A contribuição para o meio ambiente é que deve ser o cerne da questão e abrangem ainda as questões sociais.

Nesta perspectiva atual e com visão para o futuro, é fácil observarmos que a nossa situação é relativamente a mais propícia ao desenvolvimento sustentável. Afinal, o Brasil é um país democrático, com um bom crescimento econômico e de certo modo ambientalmente consciente. No entanto, falta ao país traduzir esta situação favorável em ações concretas voltadas para a transição para uma economia de baixo carbono. Apesar de algumas medidas adotadas como a definição de uma Política Nacional de Mudança Climática, a aprovação da Lei de Mudança Climática e os favorecimentos fiscais aos aparelhos domésticos da chamada "linha branca" de maior economia de energia e do declínio dos índices de desmatamento na Amazônia, muitos esforços ainda serão necessários para garantir a implementação de políticas e a adoção de práticas sustentáveis e a modernização ecológica no Brasil (NEVES; DALAQUA, 2012).

Outra questão a ser levantada é que devido aos produtos conhecidos como ambientalmente corretos muitas vezes necessitarem de um processo de produção diferenciado e consequentemente mais caro, isto reflete no valor final do produto, o que pode ser um fator decisivo durante a escolha deste produto pelo consumidor. O que impede o cidadão brasileiro de optar por produtos ambientalmente corretos muitas vezes não é somente a renda, mas a criticidade ou a falta dela em perceber e valorar a contribuição ao meio ambiente imbuída no produto, em perceber que o cidadão faz parte do meio e que optar por este produto, mesmo sendo este mais caro, proporcionaria uma melhor qualidade de vida já que contribuiria com o meio ambiente.

A ME confere importância no fortalecimento dos órgãos ambientais, na cobrança e na implementação de tecnologias limpas nas indústrias. Políticas públicas não podem ser dispersas e apenas haverá mudanças nestas políticas quando houver pressão e participação social em todas as esferas, seja na elaboração, na implementação e manutenção, na melhoria contínua ou no monitoramento e cobrança. O contexto da modernização ecológica, então, admite uma valorização do padrão econômico capitalista, reconhece a importância da atuação regulamentadora do estado em questões ambientais, admite a necessidade de movimentos ambientais para fiscalizarem tanto o governo quanto as empresas, e estas são reconhecidas como fundamentais para os processos envoltos com a modernização ecológica. Essas instituições são em geral responsáveis pelo giro econômico, pelo abastecimento de necessidades sociais básicas por meio de suas atividades produtivas e pela prestações de serviços e, ainda, pelo relacionamento intensivo com o meio ambiente.

Todas as ações devem ser pensadas dentro de um planejamento de longo prazo, algo que se 
faz difícil por inúmeras razões, algumas delas estruturais (como o curto mandato característico dos governos democraticamente eleitos) e outras circunstanciais (como a atual crise econômica). Esses obstáculos são indicações de que a transição para uma economia de baixo carbono não acontecerá sem comprometimento político e conscientização da população em especial. No entanto, é difícil imaginar um futuro em que as transformações necessárias para mitigar o aquecimento global e se adaptar aos seus efeitos inevitáveis não constarão no topo da agenda política internacional (NEVES; DALAQUA, 2012).

No que tange à questão da mudança e desempenho institucional, chega-se à constatação de que a existência de capital social pode aumentar o desempenho das instituições, tornando-as mais eficientes e responsáveis (FERNANDES, 2002).

\section{CONSIDERAÇÕES FINAIS}

Considerando todo o exposto, percebe-se que a $\mathrm{ME}$ apesar de trazer aspectos positivos não vai resolver os problemas da sociedade moderna, em especial no caso do Brasil. Entretanto, a ME poderá servir como caráter emergencial ou transitório para a passagem para uma sociedade efetivamente "Ecológica", baseada na utilização correta e racional dos recursos e na minimização dos danos ambientais.

São significativas as diferenças entre uma pessoa que extrai da natureza apenas o necessário para se alimentar e alimentar sua família, ou seja, entre o pequeno agricultor e o grande proprietário de terras. Os impactos ambientais que provocamos com o nosso estilo de vida são diferentes e diferenciados e precisam ser enfatizados e não camuflados como se adapta na afirmativa simplificadora de que o "homem destrói o meio ambiente", pois mesmo assim há pessoas que dizem estar, este processo, inserido no desenvolvimento sustentável.

Por todas estas razões, há a necessidade de se pensar numa nova política ambiental para que o país incorpore efetivamente o princípio de integração da estrutura governamental. Isso significa que as políticas executadas nas diferentes pastas do governo deveriam ser articuladas em prol da variável ambiental.

Aliada à questão governamental, a participação de uma população ambientalmente conscientizada, em todas as esferas, deve ser 'maciça e somente assim poderemos cogitar a possibilidade de alcançar ações concretas, dentre estas, a efetivação da ME no Brasil e em diferentes cenários que venham a realmente beneficiar o meio ambiente. Mesmo que dentro do discurso de sustentabilidade, a subcategoria $\mathrm{ME}$ venha ganhar espaço, ainda há muito que se rever.

\section{REFERENCIAS}

ANDRÉ, Marli Eliza Dalmazo Afonso de. Etnografia da prática escolar. 17 ed. Campinas: Papirus, 2010.

BRULLE, R. J. From Environmental Campaigns to Advancing the Public Dialog. Environmental Communication for Civic Engagement.Environmental Communication: A Journal of Nature and Culture, 4:1, 2010, p. $82-98$.

BUTTEL, F.H. Ecological modernization as social theory. Geoforum, v.31, p.57-65, 2000.

FERNANDES, A. S. A. O capital social e a análise institucional e de políticas públicas. Revista de Administração Pública, Rio de Janeiro, v. 36, n. 3, maio/jun. 2002.

FRIJNS, J.; PHUONG, P. T.; MOL, A. P. J. Ecological modernization theory and industrialising economies: the case of Viet Nam. Environmental Politics, v. 9, n. 1, p. 257-292, 2000.

GOULDSON, A.; MURPHY, J. Ecological modernisation: restructuring industrial economies. In: JACOBS, M. (Org.).Greening the millennium? The new politics of the environment. Oxford: Blackwell Publishers, p.7486, 1997. 
HAJER, M. A. The politics of environmental discourse: ecological modernization and the policy process. Oxford: Claredon Press, 1995.

LAYARGUES, P. O cinismo da reciclagem: o significado ideológico da reciclagem da lata de alumínio e suas implicações para a educação ambiental. in LOUREIRO, F.; LAYARGUES, P.; CASTRO, R. (Orgs.) Educação ambiental: repensando o espaço da cidadania. São Paulo: Cortez, 2002, 179-220.

LENZI, C. L.Modernização ecológica e a política ambiental catarinense. Revista de Ciências Humanas, Florianópolis, EDUFSC, n. 39, p. 117-134, Abril de 2006.

MARTINS, G. A.; THEÓPHILO, C. R. Metodologia da investigação científica para ciências sociais aplicadas. São Paulo: Atlas, 2007.

MILANEZ, B. Modernização ecológica no Brasil: limites e perspectivas. Desenvolvimento e Meio Ambiente, Curitiba, v. 20, p. 77-89, jul./dez. 2009.

MOL, A. The Refinement of Production. Ecological Modernization Theory and the Chemical Industry. Utrecht: Van Arkel, 1995.

MOL, A. P. J. and SPARGAAREN, Gert. Ecological Modernization Theory in Debate: a review. Environmental Politics, 2000, 9: 1.

MUNCK, L.; SOUZA, R. B. de. Desenvolvimento sustentável ou modernização ecológica? Uma análiseexploratória. SERV. SOC. REV., LONDRINA, V. 12, N.2, P. 138-138 162, JAN./JUN. 2010. Disponível em < http://www.uel.br/revistas/uel/index.php/ssrevista/article/view/7583>. Acesso em 02 fev. 2014.

NEVES, L. A. DE C; DALAQUA, R. H. De Estocolmo 72 à Rio+20: uma análise sobre a atuação brasileira nas principais conferências internacionais sobre meio ambiente e desenvolvimento 30.05.12 CADERNOS ADENAUER XIII (2012).

REIGOTA, M. O que é Educação Ambiental. Coleção Primeiros Passos 292. São Paulo, $2^{\mathrm{a}}$ ed. $5^{\mathrm{a}}$ reimpr. Ed Brasiliense, 2012. 